\title{
NON PIERCING VARIATION OF MUSCULOCUTANEOUS NERVE
}

\author{
Kishore Chandra Thakur'1, S. L. Jethani², Varuneshwar Parsad ${ }^{3}$
}

${ }^{1}$ Assistant Professor, Department of Anatomy, Himalayan Institute of Medical Sciences, Jollygrant, Dehradun. 2 Professor and HOD, Department of Anatomy, Himalayan Institute of Medical Sciences, Jollygrant, Dehradun. ${ }^{3}$ Post Graduate Student, Department of Anatomy, Himalayan Institute of Medical Sciences, Jollygrant, Dehradun.

ABSTRACT: Musculocutaneous nerve arise from lateral cord of brachial plexus and run downward \& laterally by piercing the coracobrachialis muscle in normal course and further continues as the lateral cutaneous nerve of the forearm after supplying coracobrachialis, biceps brachii and brachialis muscle. Many variations ranging from absence of nerve to non-piercing of the coracobrachialis muscle by the musculocutaneous nerve has been reported. In present study dissections of total 40 preserved upper limbs were carried out \& it was noted that in one right upper limb \& two left upper limbs, musculocutaneous nerve was not piercing the coracobrachialis. Musculocutaneous nerve passed over coracobrachialis and branch was given to coracobrachialis, biceps brachii and brachialis. It was noted in one case of left upper limb among two having non-piercing course, that after giving branch for brachialis, musculocutaneous nerve joined median nerve in lower part of arm. Surgeons need to consider these anatomical variations while exploring area near axilla and below coracoid process.

KEYWORDS: Musculocutaneous Nerve, Non-piercing, Coracobrachialis, Anatomical Variations.

HOW TO CITE THIS ARTICLE: Kishore Chandra Thakur, S. L. Jethani, Varuneshwar Parsad. "Non Piercing Variation of Musculocutaneous Nerve". Journal of Evolution of Medical and Dental Sciences 2015; Vol. 4, Issue 90, November 09;

Page: 15515-15517, DOI: 10.14260/jemds/2015/2220.

INTRODUCTION: Anterior primary rami of spinal nerves C5, C6, C7, C8 and T1 form brachial plexus. Upper trunk of plexus is formed by joining of C5 and C6 roots whereas C7 root forms the middle trunk. Lower trunk formed by joining of $\mathrm{C} 8$ and T1 roots. Medial cord is continuation of ventral division of lower trunk. Posterior cord formed by joining of dorsal division of all three trunks.

Ventral divisions of upper and middle trunk join to forms lateral cord. Musculocutaneous nerve arise in axilla from lateral cord of brachial plexus and passes downward \& laterally, pierces the coracobrachialis muscle, then run downward between the biceps and the brachialis muscle, and further continues as the lateral cutaneous nerve of the forearm. During its course nerve supplies all three muscles coracobrachialis, bicep brachii and brachialis.

The variations noticed through various studies in the course of musculocutaneous nerve in relation to the coracobrachialis muscle. Variations ranged from absence to not piercing of the coracobrachialis muscle by the musculocutaneous nerve.

These variations have clinical relevance in posttraumatic evaluations and peripheral nerve repair. It is important for anatomist \& surgeons to be aware of these possible anatomical variations to avoid unexpected complications.

AIM OF STUDY: The musculocutaneous nerve \& its variations observed in relation to coracobrachialis muscle and median nerve.

Financial or Other, Competing Interest: None.

Submission 14-10-2015, Peer Review 15-10-2015,

Acceptance 27-10-2015, Published 06-11-2015.

Corresponding Author:

Dr. Kishore Chandra Thakur,

House No. 26, Phase-2, Raj Vihar, Near F.R.I., Chakrata Road,

Dehradun-248001, Uttrakhand.

E-mail: thakurdon@yahoo.com, bestthakur@hotmail.com

DOI:10.14260/jemds/2015/2220.
MATERIAL AND METHODS: The dissections of total 40 preserved upper limbs from formalin fixed cadavers were carried out according to the instructions by Cunningham's manual of practical anatomy. Both upper extremities (Right and left) of the body were dissected. The axilla and the arm were dissected to expose brachial plexus \& musculocutaneous nerve from origin up to cubital fossa.

\section{Criteria followed for selection of specimen:}

1. Specimen with intact and undisturbed muscle arrangement included in study.

2. Limb with damaged nerve and muscular arrangement discarded.

3. Limb with any injury mark not included in study.

Musculocutaneous nerve identified at level of origin and traced till cubital fossa to look for number of cases where musculocutaneous nerve does not pierce coracobrachialis muscle.

\section{OBSERVATIONS:}

1. The musculocutaneous nerve did not pierce the coracobrachialis muscle in three upper limbs among 40 (Figure 1).

2. Unilateral variation noticed in two left upper limbs \& one right upper limb of three different cadavers (Figure 1).

3. In one case of left upper limb, musculocutaneous nerve was joining with median nerve approximately $6.4 \mathrm{~cm}$ distal to branch for bicep brachii muscle (Figure 1).

After dissection of all 40 upper limbs, it was noted that in one right upper limb \& two left upper limbs; musculocutaneous nerve was not piercing the coracobrachialis.

Musculocutaneous nerve passed over coracobrachialis and branch was given to coracobrachialis, biceps brachii and brachialis. It was noted in one case of left upper limb, that after giving branch for brachialis, musculocutaneous nerve was joining the median nerve (Figure 1). 
In all other upper limbs normal course of musculocutaneous nerve was seen on dissection, in which musculocutaneous nerve were piercing coracobrachialis of its respective side and giving branch to coracobrachialis, biceps brachii and brachialis muscles (Figure 2).

DISCUSSION: The coracobrachialis muscle lost one head and remaining two heads out of three, got fused during course of human evolution.\{1\} and that's why appears piercing this muscle. Le minor reported that the coracobrachialis muscle not pierced by musculocutaneous nerve.\{2\}

The reported variations of the musculocutaneous nerve not piercing coracobrachialis also noted by Nakatani $\mathrm{T}$ et al.(3)

The musculocutaneous nerve was found to not pierce the coracobrachialis in 3 limbs (left) out of 50 limbs:\{4\} Nayak $S$ et al. reported about non-piercing musculocutaneous nerve to coracobrachialis in one limb.(5) Chitra R. also observed that the musculocutaneous nerve did not pierce the coracobrachialis muscle in two cases.(6)

Suma M \& Shradha I. found in $7.5 \%$ cases $(3 / 40)$ that musculocutaneous nerve not piercing coracobrachialis on

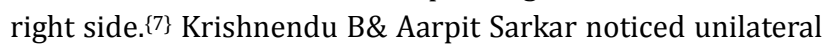
variation of musculocutaneous nerve not piercing coracobrachialis in 2 cases of two different male cadavers.(8)

In present study musculocutaneous nerve not piercing coracobrachialis was seen in three cases. The incidence of variations observed is $2.5 \%$ in female, $5 \%$ in male \& $7.5 \%$ in total.

The different types of communications between the musculocutaneous nerve and the median nerve are frequently observed along with or without musculocutaneous nerve piercing the coracobrachialis.(6) $\mathrm{Li}$ Minor.(9) Venieratos and Anagnostopoulou(10) and Choi et al.(11) classified communication between the MSCN and the MDN. These communications classified into five types by Li Minor.(9) Venieratos and Anagnostopoulou.(10) classified three types of communication between MDN and MSCN taking coracobrachialis muscle as the reference point.

Type I- proximal communication i.e. before entrance of the MSCN into coracobrachialis.

Type II- distal communication i.e. after exit of MSCN from coracobrachialis.

Type III- MSCN nerve and the communicating branch did not pierce the coracobrachialis.

In present study, incidence of communication between MSCN \& MDN is $2.5 \%$, as in one case of left upper limb where musculocutaneous nerve did not pierced coracobrachialis muscle and joined median nerve in lower third part of arm and thus it can be kept under type III of Venieratos and Anagnostopoulou classification. Prasada Rao and Chaudhary reported unilateral communication of MSCN to the MDN in eight cases and bilateral in two cases.[12] Chauhan and Roy observed communication between the MDN and MSCN in their study. [13]

This study supports the idea of various researchers, who claims that MDN nerve formed by three roots, based on observation of the musculocutaneous nerve joining the MDN. Different researchers gave opinion that instead of having two roots MDN may have three roots - either one each from lateral cord, medial cord and MSCN.\{13\},\{14\} or two from lateral cord and one from the medial cord by Mohapatra et al. $\{15\}$

Communication between MSCN and MDN can be explained on embryological base considering role of various molecules \& many signaling transcription factors which directly or indirectly defines and controls the formation of the limbs \& its muscles along with nerves. Misinterpretation or failure of expression of any responsible factors, leads to abnormalities in the formation and its nerve distribution.

CONCLUSION: During shoulder surgery or working near axilla and below coracoid process, it is important to identify the musculocutaneous nerve keeping different variations in mind, as it is prone to injury otherwise. Surgeons need to consider these anatomical variations when trying to explain unusual added symptoms related to median nerve injury along its course of distribution.

\section{REFERENCES:}

1. Datta A.K. Essentials of Human Anatomy part III,4th ed.calcutta:cbi; 2009; p50-51.

2. Le Minor JM .A rare variation of the median and the musculocutaneous nerves in man. Archives Anatomy Histology Embryology. 1990; 73: p33-4215.

3. Nakatani T, Mizukami S, Tanaka S. Three cases of the musculocutaneous nerve not perforating the coracobrachialis muscle. Acta Anat Nippon. 1997; 72: p191-4.

4. Jamuna M, Amudha G. Journal of Clinical and Diagnostic Research.

2011 November (Suppl-1), Vol-5(6): p1144-1147.

5. Nayak S, Samuel VP, Somayaji N.Concurrent variations of the median nerve, the musculocutaneousnerve and the biceps brachii muscle. Neuroanatomy.2006; 5:30-2.

6. Chitra R. Multiple bilateral neuroanatomical variations of the nerves of the arm. Neuroanatomy.227; 6: p43-5.

7. Suma M, Shradha I, International journal of general medicine and pharmacy. vol 2, issue 4,sep 2013, p53-64.

8. Krishnendu B, Aarpit S, International journal of current research review, march 2014, vol 06(06), p75-79.

9. Li Minor JM. A rare variant of median and musculocutaneous nerves in man. Archives Anatomy Histology Embryology 1992; vol. 73, p. 33-42.

10. Venieratos D., Anagnostopoulou S. Classification of communications between the musculocutaneous and median nerves. Clinical Anatomy.

1998, vol. 11, p. 327-331.

11. Choi D., Rodriguez-Niedenfuhr M., Vazquez T., Parkin I, Sanudo JR. Patterns of connections between the musculocutaneous and median nerves in the axilla and arm.ClinicalAnatomy,2002,vol.15,n.1,p.1117.PMid:11835538. http://dx.doi.org/10.1002/ca.1085.

12. Prasada Rao PV, Chaudhary SC. Communication of the musculocutaneous nerve with the median nerve. East Afr Med J. 2000; 77: p498-503.

13. Chauhan R, Roy TS. Communication between the median and musculocutaneous nerve - a case report. J Anat Soc India. 2002; 51: p72-75. 
14. Saritha S. Variations in the median and musculocutaneous nerves-A surgical prospective. Journal of Anatomical Society of India, 2004, vol. 53, n. 1, p. 3166.
15. Mohapatra BB. Chinara PK., Dutta BK., Nayak AK. Variation in the formation and branching pattern of median nerve. Journal of Anatomical Society of India, 2004, vol. 53, n. 1, p. 31-66.

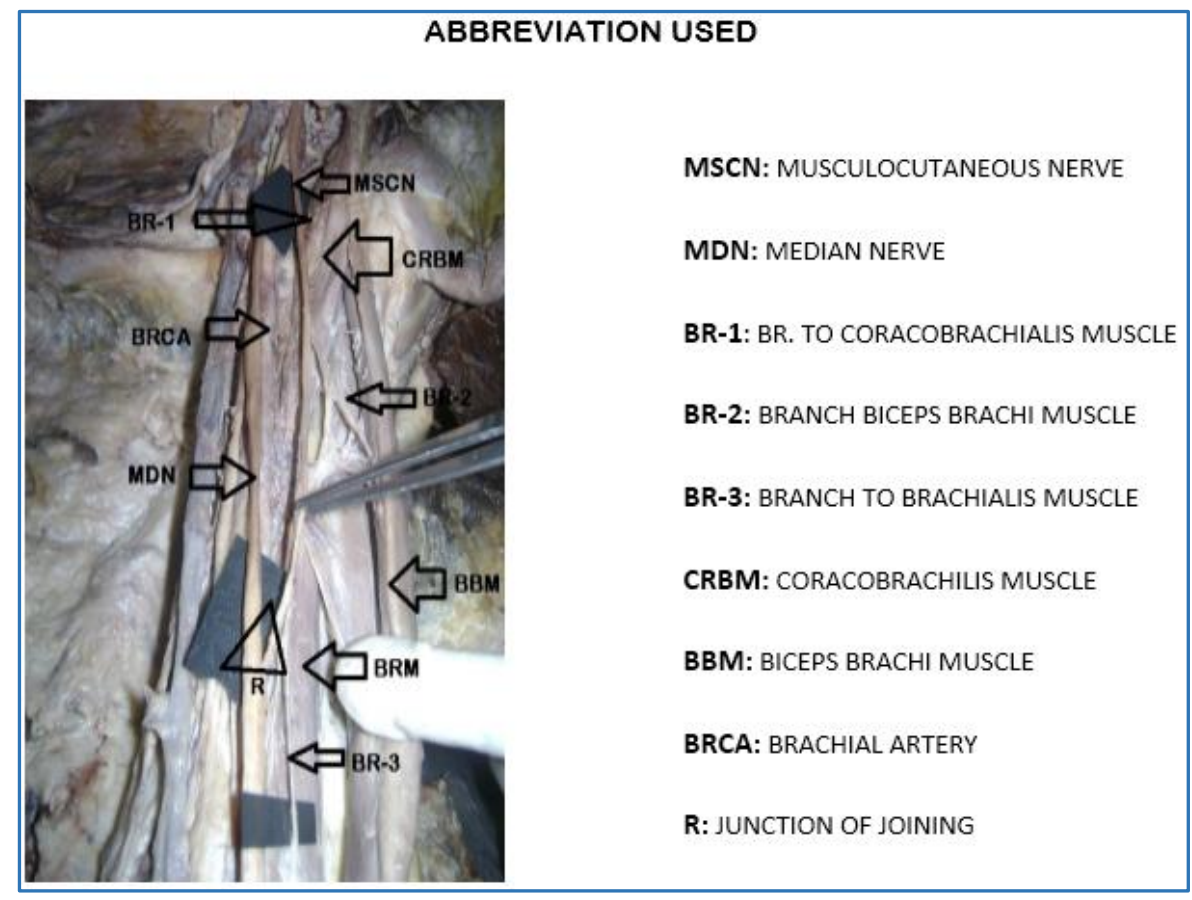

Fig. 1: Left upper limb: MSCN not piercing coracobrachialis Muscle \& joining median nerve

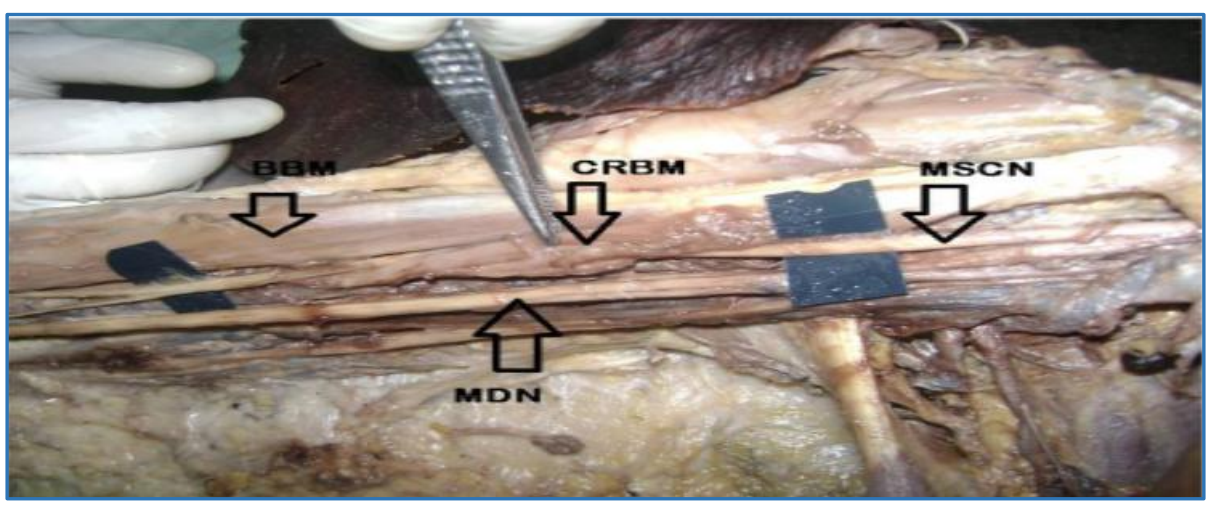

Fig. 2: Upper limb: MSCN piercing coracobrachialis Muscle (Most common course) 